\title{
EDITORIAL
}

\section{A bag of pretzels}

International Journal of Impotence Research (2007) 19, 441-442; doi:10.1038/sj.ijir.3901594

Marty Resnick passed away on 24 June 2007. Marty was the Lester Persky Professor and Chairman of Urology, Case Western Reserve University, editor of the Journal of Urology, a well-known surgeon and an author of many papers and books. Marty was secretary, then president of the American Urological Association (AUA). He was a man of many accomplishments.

Marty, curiously, liked pretzels. I am not quite sure when Marty began eating pretzels, or just what kindled his interest in pretzels. There was no doubt about it, however, that Marty liked to eat pretzels.

I first met Marty some time in 1986, when I interviewed for my urology residency at Case Western Reserve University. Marty was quite pleasant, diplomatic and straightforward. I do not recall Marty eating pretzels then. The interview lasted a few hours, limiting my ability to observe any pretzel-eating activity.

It was during my years as a urology resident that I noticed Marty enjoying pretzels at various times. The moments were unpredictable. Being a young, naïve urology resident, I did not attempt to attribute any significance to Marty's pretzel-eating behavior.

Upon my return to Case Western Reserve University as a junior faculty member in 1992, I immediately took note of Marty's pretzel-eating behavior and set out to identify the specific time associations wherein eating pretzels was most likely. Sort of a quasi-scientific study.

Pretzels became part of our vernacular, a part of our culture. Marty brought a bag of pretzels into my office on a routine basis to share and talk, and pretzels led to many unique opportunities for frank discussions. Marty and I discussed politics, religion and academics. I learned of his youth, his passions, his life and his mission. We spent hours discussing the pros and cons of academics. Marty loved academics and he directed my research endeavors. He taught me the nuances of writing a good academic paper and how to be a good academic doctor. Marty was truly committed to the academic mission. What I observed was that pretzel-eating was limited to the office, during times of reflection and during moments of discussion. Pretzel-eating was not a random event, but a purposeful, intricate part of our academic mission. Pretzels were an entree into many areas that could not be discussed in an open forum. Pretzels were permission giving.
Marty was keenly interested in my perception of the AUA, the annual AUA meeting and the Journal of Urology. I was fortunate in that I was appointed to the AUA's 'Young Urologists Committee'. I was glad to learn that I was considered a young urologist. I think Marty liked having me on that committee. He could just walk down the hall to my office to gain my 'young urologic' insights. All he had to do was to bring a bag of pretzels along to get the conversation started.

As an aside, Marty reminded me that one had to be careful when eating pretzels and attempting to speak. Conversations are tough when chewing pretzels. There was a skill to eating pretzels and holding a conversation. Sort of pretzel etiquette.

Pretzel conversations included the AUA meeting. While Marty was secretary, I had suggested that the meeting cover more basic science research. He noted that the meeting was attended by and intended for practicing urologists. During his tenure as AUA secretary, he changed the face of the AUA meeting, making it more clinical. Marty was quite proud of this accomplishment. He left his personal imprint on the AUA meeting.

I had suggested that the AUA meeting needed to move to an all on-line format. Paper submissions were passé. Marty argued that the more senior urologists would never give up their slides; would never use PowerPoint; and would never use an online submission process. I argued that the AUA would need to train the senior urologists in the use of PowerPoint, that on-line submissions were necessary and that the AUA's slowness to adapt to this new technology made the AUA seem out of touch. It took a while and lots of pretzels, but Marty finally listened.

The Journal of Urology was another 'pretzel' topic. The journal was behind the times when Marty was AUA president, and as he assumed editorship, I argued that an on-line submission process was being used by many journals and was much more efficient than paper submissions. Marty argued that the more senior urologists would never learn how to submit a paper on-line; would never understand the on-line review process and would never accept reviewing a paper if it were submitted on-line. Many pounds of pretzels were needed to discuss these items in depth. Fortunately, Marty and the AUA agreed to these changes.

Marty thought the journal was too large and unwieldy and also disliked case reports. He shortened the journal, did away with the case reports 
and increased the rejection rate. He left his imprint on the Journal of Urology and was quite proud of this accomplishment.

Marty visited my office last April after returning from the European Urology Association meeting. He was tired and was not feeling well. He did not bring a bag of pretzels with him and kindly declined my offer to share pretzels during that visit. This was an ominous sign as Marty was diagnosed with acute myelogenous leukemia (AML) shortly thereafter. He fought AML with great courage for over a year. During my many visits to his hospital room, he was not up to sharing any pretzels. The chemotherapy altered his ability to taste food, or he undoubtedly would have joined me. In spite of the lack of pretzel conversation, Marty still held meetings, spoke to the Dean, the hospital president and other high-ranking officials and continued in his capacity as editor of the Journal of Urology, all while undergoing treatment for AML. Marty was committed to academics.
He set an example for all to follow, and he set a very high bar.

It is now a few days since Marty's funeral. I sit in my office with a bag of pretzels reflecting on all of Marty's remarkable accomplishments and recounting our numerous conversations. I take a handful of pretzels down the hall to his office expecting to find him there, ready for pretzel dialogue. Saddened by his absence, I return to my office and reminisce. Then, one of the urology residents walks into my office. I offer a pretzel. He accepts. We talk about politics, religion and academics. We continue the tradition and our conversation, all the while sharing a bag of pretzels.

AD Seftel

Department of Urology, Case Western Reserve University, Cleveland, $\mathrm{OH}, \mathrm{USA}$ E-mail: Allen.Seftel@case.edu 